\title{
A Study on the Public Perception of Waste-to-Energy Facilities in Metro Vancouver
}

Carol Leung ${ }^{1}$, Helen Heacock ${ }^{2}$

${ }^{1}$ Lead Author, B. Tech Student, School of Health Sciences, British Columbia of Institute of Technology, 3700 Willingdon Ave, Burnaby, BC, V5G 3H2

${ }^{2}$ Supervisor, School of Health Sciences, British Columbia of Institute of Technology, 3700 Willingdon Ave, Burnaby, BC, V5G 3H2

\section{ABSTRACT}

BACKGROUND: Metro Vancouver is proposing a second waste-to-energy (WTE) facility to be built within the regional district. WTE facilities are used to reduce the volume of waste going to landfill sites. With Metro Vancouver's desire to become the Greenest City in the World by 2020, WTE facilities are one option to achieve this goal. The proposal is currently in its second phase, and is looking for an ideal location. However, there are debates over whether the use of WTE facilities is an ideal method of municipal waste disposal. The aim of this research project was to measure the public knowledge and opinion of WTE facilities across various demographics.

METHODS: A survey regarding knowledge and opinion of WTE facilities was generated and distributed online via social media platforms. Microsoft Excel and NCSS software were used to analyze the data to determine statistical significance.

RESULTS: There were a total of 111 respondents. Demographic information was analyzed against the respondent's knowledge score of WTE facilities. There is no statistically significant difference between educational background, age group, or place of residence and attaining a particular knowledge score of WTE facilities ( $\mathrm{p}=0.51, \mathrm{p}=0.31, \mathrm{p}=0.22$ respectively). The results indicated a limited knowledge of WTE facilities in the general public, with a mean score of 3.6 out of a maximum of 5. 59\% of respondents indicated that they felt neutral towards WTE facilities, while $24 \%$ believed they were the most desirable method of managing municipal waste, and $21 \%$ believed they were least desirable.

CONCLUSION: Results suggests that WTE facilities are not well understood, and not enough knowledge has been provided to the public in order for them to formulate a consensus on supporting or rejecting the use of WTE facilities. In such cases, the Environmental Health Officer (EHO) can act as an educator to help the public make an informed decision on the effects of WTE facilities and the consequences of different methods of handling municipal solid waste.

Key words: survey, waste-to-energy facilities, public perception, air quality, waste management 


\section{INTRODUCTION}

Metro Vancouver is one of the regional districts located in British Columbia, Canada and has a population of 2.4 million people. As the third largest metropolitan area in Canada, waste management and disposal poses to be a very prominent responsibility of Environmental Health Officers (EHO). An increased reliance on Waste-to-Energy (WTE) facilities and movement away from landfills will change the public health risks posed by municipal solid waste disposal as it is currently known. EHOs have a responsibility to provide advice and education to the public on waste disposal practices. Thus, it is important for officers to be aware of the changes and any possible health risks. By knowing the public's perception of emerging waste disposal methods, EHOs can more easily handle any possible public concerns and accurately represent the opinions of their organizations. In this paper, the author will discuss the background on WTE technology and its uses, as well as Metro Vancouver's waste disposal plan. Finally, the results of a public opinion poll regarding the use of WTE facilities will be discussed.

\section{STATEMENT OF THE PROBLEM \& PURPOSE OF RESEARCH STUDY}

The only previous investigation that has already been conducted into the public perception of WTE facilities was not an in depth examination of the issues. Abacus Data surveyed 1,000 eligible voters to represent the opinions of Metro Vancouver. It was reported that only $32 \%$ of surveyed residents agree that WTE facilities are an optimal alternative for waste management, possibly suggesting that WTE facilities are an undesirable option in the eyes of Metro Vancouver residents. This leads to the question: if the public was fully informed of the intentions of building this WTE facility, would their opinion change?

The purpose of this research project is to assess the actual knowledge of WTE facilities and its perceived benefits or disadvantages from the public residing in the Metro Vancouver area. Specifically, factors such as education and demographic region were identified and analyzed to determine their effect on the public's perception of WTE facilities.

Performing a public opinion poll is important because the results can potentially change the decisions of the government. Conversely, it is helpful to know what the public already knows or does not know, in order to develop more effective messages to reach and fill these gaps without being repetitive. An important factor is to determine what the public already knows and use that information to leverage the way an $\mathrm{EHO}$, as credible educators, can change the public perception.

\section{LITERATURE REVIEW}

\subsection{Waste-to-Energy Facilities}

WTE technologies convert municipal waste into energy such as electricity, hot water, steam, and fuel (Metro Vancouver, 2014b).

Waste is preprocessed at the residential level, by separating out the recyclables and compostables. The recyclables are collected using Metro Vancouver's blue bin program or can be taken to the recycling depot (City of Vancouver, 2015). The compostables are collected in the green bin to be used for city compost (City of Vancouver, 2015). The remaining waste that cannot be recycled or composted can either be sent to a landfill or a WTE facility. If it is sent to the WTE facility, the waste is burned and converted into energy. The ash that is leftover is greatly reduced in quantity and is sent to the landfill. 
There are three ways WTE facilities can convert waste to energy:

\section{Mass-burn incineration}

Mass-burning is the most common method used in WTE facilities. This is the current technology that is used in Metro Vancouver's only WTE facility, which is located in Burnaby. In this facility, waste is collected by trucks and placed into storage. 850 tonnes of waste collected from the municipality is incinerated each day without further preprocessing at the site (Covanta, 2015). Much of the waste is from single family homes. In this method, if the waste is not already sorted before collection, recyclables such as paper and metals will be incinerated. The waste is lifted by an overhead crane into the combustion chamber (United States Environmental Protection Agency, 2014). The heat released from combustion of the waste is used to convert water to steam. The generated steam is sent to a turbine generator that produces electricity to be used at or sold by the facility (United States Environmental Protection Agency, 2014). Specifically in Metro Vancouver's case, the electricity that is generated is sold to British Columbia Hydro (Convanta, 2015). The remaining ash is sent to a landfill, and any particulates that are released from the combustion is removed by filters before they can be ventilated into the air (United States Environmental Protection Agency, 2014).

\section{Gasification and pyrolysis}

Gasification and pyrolysis is another way waste can be converted to energy. While mass-burn incineration fully converts waste into energy and ash, gasification and pyrolysis converts waste into intermediates that can be further processed (Juniper Consultancy Services Ltd., n.d.). This process produces gases, oils, and solid char which can be used and sold as fuel or processed for other applications (Juniper Consultancy Services Ltd., n.d.). Although this method of converting waste to energy can increase recycling rates and address environmental concerns, it requires extensive preprocessing of the waste. Therefore, it is not as commonly utilized as mass-burn incineration (Juniper Consultancy Services Ltd., n.d.).

\section{Refuse-derived fuel}

Refuse-derived fuel systems involves first removing metals, glass, grit, and other non-combustible materials from the waste (Metro Vancouver, 2014b). The remaining waste can either be burned using the processes described above or sold to be used as a replacement for coal (Metro Vancouver, 2014b). This process involves many more steps than the previous two processes described above, and therefore is also less commonly used.

\subsection{Concern of WTE Facilities}

When comparing the use of WTE facilities to landfills, WTE facilities appear much more attractive. They are able to reduce the amount of landfill space required; they do not directly pollute groundwater by leaching; and surprisingly, landfills are found to cause greater environmental and health risks by air emission than incineration (Bridges et al, 2000). However, emissions from WTE facilities may also cause human and environmental health issues that are not yet well understood. Many pollutants are emitted from solid waste incineration and may affect human and environmental health negatively.

Dioxins are of particular concern. By incinerating ordinary household waste, toxic substances such as dioxins will be created (Health Canada, 2005). Sources of dioxin exposure is mainly due to meat, dairy, fish, and shellfish (WHO, 2014). However, dioxins can be released into the environment due to incomplete combustion in WTE 
facilities (WHO, 2014). Classified as persistent environmental pollutants (POPs), they can cause issues in the reproductive system, the immune system, interfere with hormones, and can increase the risk cancers (WHO, 2014). The harms of dioxin emissions, along with the other particles such as greenhouse gases, heavy metals, and nanoparticles, are often the issues that the general public picture when WTE facilities are discussed.

\subsection{Existing Facilities Worldwide}

On a global scale, WTE facilities are a method of waste management in North America, Europe, as well as Asia (Metro Vancouver, 2014b). A notable example of a WTE facility recently put into commission in Canada is the Enerkem Albert Biofuels facility, which is expected to help the City of Edmonton's waste diversion rate increase from $60 \%$ to $90 \%$ (Enerkem, 2010). Rather than generate electricity, like the current
WTE facility in use in Metro Vancouver, the facility in Edmonton produces biofuels from non-recyclable and non-compostable municipal solid waste (Enerkem, 2010). The technology uses the gasification process described previously, and will produce methanol, ethanol, and other chemical intermediates, which can be used as transportation fuels or for the production of other every day products (Enerkem, 2010). Although the technology appears promising, this facility is the company's first full-scale commercial plant and was officially in commission only in June of 2014. Therefore, any possible unforeseen challenges have yet to be seen.

Figure 1 shows a map of all the European WTE plants facilities in use in 2012. WTE facilities are widely used in Europe to reduce their dependence on landfills (CEWEP, n.d.). In Europe, the view on waste management is that quality recycling should be of primary focus.

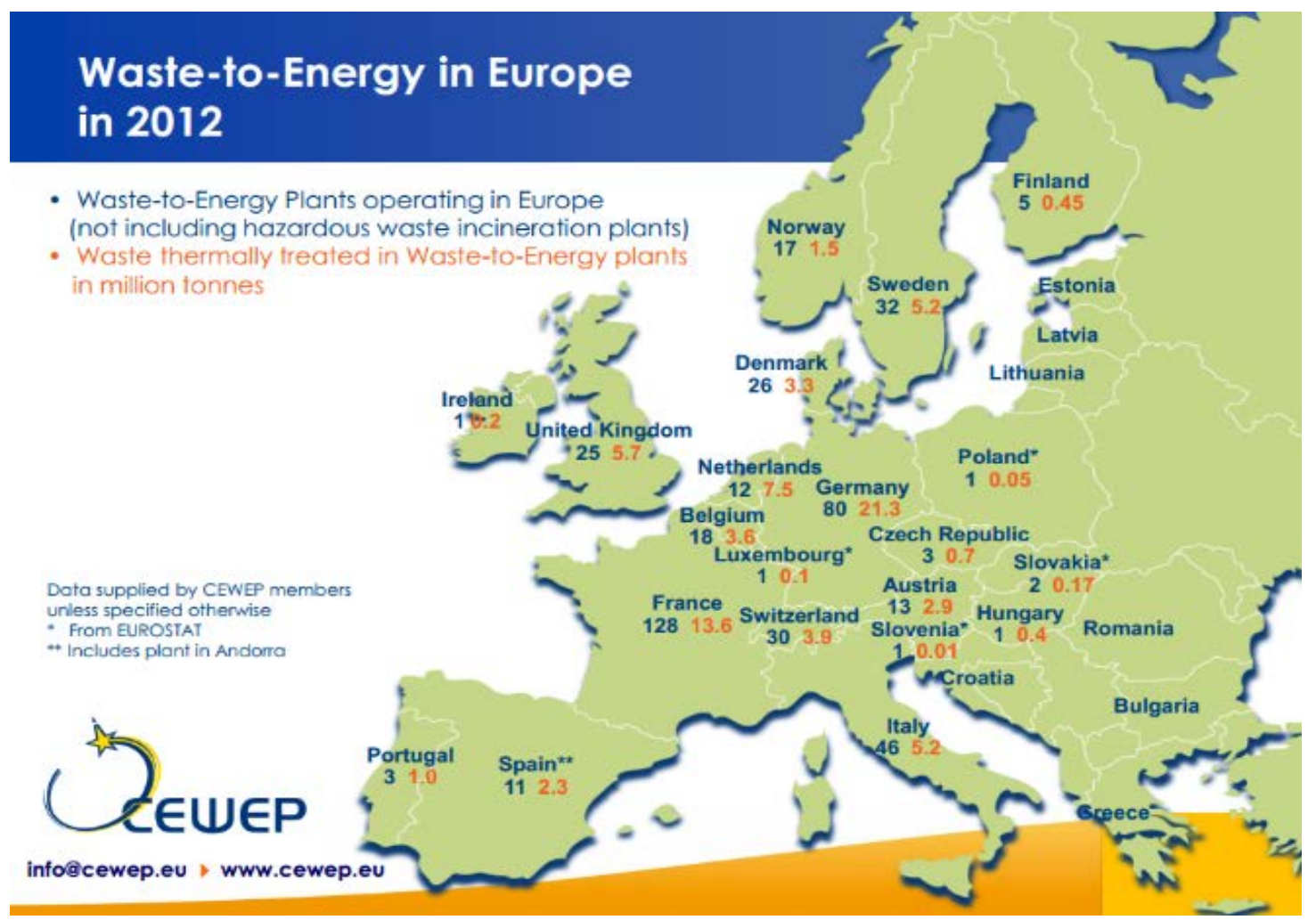

Figure 1 (CEWEP, 2012) 
However, for the remaining waste that cannot be recycled, converting them from waste to other usable energy sources is a better solution than having the waste degrade in a landfill (Stengler, 2015). Despite this argument, not all groups in Europe agree with this view. Three advocacy groups, the Global Alliance for Incinerator Alternatives (GAIA), Health Care without Harm (HCWH), and the Bankwatch Network are campaigning in conjunction for a change in the European Union legislation to move away from incineration and focus efforts in increasing waste diversion rates and enhancing producer responsibility (Simon \& Hlebarov, n.d.). The groups bring in the debate that incineration is not a clean source of energy, and can potentially result in recyclables being incinerated. They explain that the amount of energy that is generated is small, compared to the benefits that could be reaped from reprocessing recyclables (Simon \& Hlebarov, n.d.). It can be seen that there is debate over the benefits and drawbacks of WTE facilities in all parts of the world where they are used widely, and scientists have not agreed on one mutual view.

\subsection{Metro Vancouver's Plan}

Metro Vancouver is comprised of 21 municipalities, one Electoral Area and one Treaty First Nation (Metro Vancouver, 2014a). In July 2010, Metro Vancouver created the Integrated Solid Waste and Resource Management Plan (ISWRMP) to manage Metro Vancouver's solid waste. This plan outlines a waste reduction campaign and a system to recover materials and energy from any generated waste (Metro Vancouver, 2010). The plan has four major goals, one of which includes the "[recovery of] energy from the waste stream after material recycling” (Metro Vancouver, 2010).

Metro Vancouver claims that WTE facilities are the most effective in extracting energy from the waste stream after recycling
(Metro Vancouver, 2010). The ISWRMP stated that Metro Vancouver will continue the use of the existing WTE facility in Burnaby to achieve its goals. It was also proposed that in 2015, expansion in this area will be initiated (Metro Vancouver, 2010). The plan explained that expansion will entail increasing the capacity of the existing facility or creating a new WTE facility to encompass nearly double the capacity of the existing Burnaby facility (Metro Vancouver, 2010). Primarily, Metro Vancouver's plan to expand the WTE facility is to reduce the pressure on having to allocate additional landfill space. In addition, energy that is extracted from incinerating municipal solid waste will help offset some of the facility's operation costs (Metro Vancouver, 2014b).

As a part of becoming the Greenest City in the world by 2020, waste reduction and diversion from landfills and incineration is a prominent component of the action plan. The Green Bin Program which is currently in place in some municipalities of Metro Vancouver, allows residents in houses, duplexes, and some multi-unit buildings to collect their compostables in their Green Bin. The Green Bin is then collected by the City to be recycled into compost and soil for use within the region (City of Vancouver, 2015). The Green Bin Program will prepare the region for a ban on organic waste disposal at the landfill, which is estimated to start sometime in 2015 (City of Vancouver, 2015). A well-established recycling program in Metro Vancouver is the Blue Box program. Recyclable materials such as glass containers, paper, and aluminum cans, are set out at the curbside in the Blue Box or taken to a recycling depot (City of Vancouver, 2015). Such materials can be converted into new raw materials and recycled into new products (Multi Material BC, 2015).

The rationale for building this incinerator is that even if the Metro Vancouver region reaches the goal of an $80 \%$ 
recycling rate, it is estimated that there will be still 700, 000 tonnes of waste that needs to be disposed of annually (Metro Vancouver, 2014b). Out of this, it is stated that the proposed WTE facility will be able to handle 370, 000 tonnes of waste, while the existing WTE facility would handle 280, 000 tonnes, thus leaving only 50, 000 tonnes to be sent to the landfill annually (Metro Vancouver, 2014b). This strategy will ultimately reduce the region's reliance on landfill space, which is why the National Zero Waste Council is proposing this facility on behalf of Metro Vancouver (National Zero Waste Council, 2014).

Under the provincial Environmental Management Act, municipal solid waste incinerators are listed as a high risk operation, as described in the Waste Discharge Regulation. Incineration of municipal solid waste is considered to be a high risk activity to the environment and public health. Therefore, facility operators are required to obtain a permit or approval to authorize their discharges in order to protect the air quality of British Columbia (Waste Discharge Regulation, 2004). There is also a Ministry of Environment guideline for emissions from Municipal Solid Waste combustion. The conditions and limits outlined in the guidelines apply to mass burn facilities, such as the existing Burnaby WTE facility, as well as the proposed facility. Avoiding outdoor air contamination is one of the considerations that Metro Vancouver has in mind. Typical air pollutants which may be released into the atmosphere include: particulate matter, carbon dioxide, sulfur dioxide, nitrogen oxides, acidic compounds, metals, and organic compounds (Ministry of Environment, 2011). According to the guidelines, WTE facilities should ensure that the public has online access to Continuous Emission Monitoring System (CEMS) data (Ministry of Environment, 2011). However, the CEMS data for the Burnaby WTE facility could not easily be accessed on the facility's website by the author and the most recent report was from April 2013 on 2012 data. It was found that all air emission related parameters monitored in 2012 were in compliance with the requirements (Allan, 2013).

Despite the existing guidelines and legislation, the building of this new WTE facility has not been met with welcoming arms. Due to the negative image of burning garbage, the new WTE facility has been deemed a bad idea that is harmful to the environment and human health. Such opinions are being reflected in news articles that can be found in the Huffington Post (Travis, 2014), the Vancouver Sun (Constantineau, 2014), as well as the Globe and Mail (Bula, 2014). A website, "stoptheincinerator.com" has been created to outline the negative aspects in Metro Vancouver's plan and states the problems associated with incinerators (Stop the Incinerator, 2014). The "Stop the Incinerator" campaign posters appears in many public areas all over the regional district, such as on bus shelters, and is gaining much public attention. The website warns that expanding the WTE sector will be a drain on tax dollars. It states that instead of encouraging recycling, it will simply turn to burning materials such as recyclable plastics to keep the facility running (Stop the Incinerator, 2014). The website also addresses several concerns, including the building of an incinerator will not eliminate landfills, but rather will depend on it (Stop the Incinerator, 2014). Also, the website discusses some regulation concerns. It explains that although the facility may claim to have advanced air pollution controls, the Ministry of Environment's regulations may not be strict enough to keep such facilities in check (Stop the Incinerator, 2014). 


\subsection{A Gap in Understanding}

The issue present lies not in finding the appropriate technology to treat municipal solid waste, but solving the issue of having a negative public perception. A negative public perception poses a great barrier to moving technology forward and being able to implement the technology. In the United Kingdom (UK), it was found that the siting decision process for a new incineration plant is lengthened due to objections from the local community (Petts, 1991). This leads to additional open discussion panels of risks and benefits to the public, thus further prolonging its implementation. Ultimately, the findings indicated that delays meant costly proceedings and a lack of confidence from the community towards the decision-makers (Petts, 1991). Petts found that the negative perception of waste incineration is more complex than a lack of understanding. The public may understand a message from an expert regarding the topic, but they will refuse to agree with the message simply because of the judgment they already hold prior to receiving the message (Petts, 1991). Ultimately, Petts recommends building the public's confidence in the professionalism of the waste industry with education, training, and enforcement of standards (Petts, 1991). In Metro Vancouver's case, it is important to understand the state of the public perception on WTE facilities so that campaigns can be successfully implemented to gain trust from the public.

A more recent example of public opinion being a factor that is carefully considered is the proposal for building a WTE facility in the UK. It was recognized that the public perception of WTE facilities are linked with existing older facilities, which are prone to issues of pollution and exceeding emissions (DEFRA, 2013). The Department for Environment Food \& Rural Affairs of the UK emphasized the importance of proactive communication with the public. Strategies such as using realistic models, virtual walkthroughs, and artist impressions of the facility were used to accurately inform the public (DEFRA, 2013). Public consultation and engagement was found to be an important aspect in gaining acceptance for waste management development (DEFRA, 2013).

\subsection{Assessment of Metro Vancouver}

So far, only one public survey has been conducted on the issue of the public concern on Metro Vancouver's plan on incineration. The survey was performed by Abacus Data in 2014 on behalf of NextUse Recycling Ltd. and asked the public's opinion on the waste management options for Metro Vancouver. 1, 021 eligible voters were surveyed online to represent the opinions of those living in the Metro Vancouver area (Abacus Data, 2014). The Globe and Mail published an article on September 16, 2014 reporting on this survey and stated that $90 \%$ of the survey's respondents would like Metro Vancouver to move away from building a new incinerator and investigate facilities that can mechanically sort recyclables instead (Bula, 2014). However, there are mixed results with the actual opinion of incineratoruse. When asked whether "trucking waste to incinerators and burning it, then trucking the ash to landfill" on the survey, 32\% of respondents said this is one of the better ways to process the waste, $39 \%$ said this is one of the worst ways, and $28 \%$ were unsure (Abacus Data, 2014).

The Globe and Mail article only reported that $32 \%$ of the respondents thought incinerators were a good option, without mentioning the other two numbers shown in the survey (Bula, 2014). The issue with reporting only one number is that the picture that is painted for the reader appears to be that $32 \%$ of respondents thought incinerators were a good option, while the rest thought incineration was bad. However, this is not the 
case. The respondents are actually quite evenly distributed between the three responses. This indicates that the respondents, as a collective, may not be knowledgeable enough on the topic area to make an informed decision. The results of the survey also do not mention the specific region of Metro Vancouver the respondents are from, nor their educational background.

Furthermore, rather than calling the incineration technology a "waste-to-energy facility", the survey simply called them incinerators, possibly creating a negative perception. There is also no mention of the energy that is recovered from incineration. This stands in contrast with the other option of "trucking waste to facilities which use technology to sort [,] ... recover and recycle" garbage (Abacus Data, 2014). The latter option implies that there is no actual waste and everything is recycled, which is untrue with the current existing materials recovery technology.

NextUse Recycling Ltd. is a British Columbia-based business that utilizes advanced technology to maximize recycling and materials recovery. Due to the fact that this survey was performed on behalf of NextUse Recycling Ltd., the survey seemed to be biased towards the support of developing materials recovery facilities in Metro Vancouver. This is where the author's study attempts to fill in the gap in current knowledge. The study attempted to neutrally assess the gap between the actual knowledge of incinerators and the public's opinion of them to determine whether a lack of knowledge is linked with public resistance. Not only will this help Metro Vancouver shape its campaign to gain public support for its proposed facilities, it can also set a precedent for guidance in future implementations of novel technology.

Public opinion surveys are important in allowing the voices of the general public be heard. The expression of public opinion is able to cause changes in policy (Emery, 1994). Conversely, if decision-makers are able to influence public opinion through education or persuasion, policy changes may be swayed to their favour with public support (Emery, 1994). In either case, understanding public knowledge will help Metro Vancouver either change its proposal to align with current state of opinion in the community, or design campaigns that aim to educate and persuade the community. Most importantly, this will help the National Zero Waste Council build up credibility in support of their long term waste-reduction plans.

\section{METHODS AND MATERIALS}

\subsection{Description of Standard Methods}

A survey was conducted in Metro Vancouver in January 2015 to determine the public perception and knowledge of the use of (WTE) facilities. Responses from survey participants who self-identify as residing in Metro Vancouver were included in the analysis. Metro Vancouver includes the following municipalities: Village of Anmore, Village of Belcarra, Bowen Island Municipality, City of Burnaby, City of Coquitlam, Corporation of Delta, City of Langley, Township of Langley, Village of Lions Bay, City of Maple Ridge, City of New Westminster, City of North Vancouver, District of North Vancouver, City of Pitt Meadows, City of Port Coquitlam, City of Port Moody, City or Richmond, City of Surrey, Tsawwassen First Nation, City of Vancouver, District of West Vancouver, City of White Rock, and Electoral Area A (Metro Vancouver, 2014).

The questionnaire consisted of closed ended questions to reduce ambiguity. A prize incentive was offered for participants who were interested in submitting their email address to be entered into a draw. At the end of the questionnaire, participants were encouraged to forward the survey to their contacts. The data gathered was organized 
using Microsoft Excel (Microsoft, 2014a), and analyzed in NCSS 9 (Hintz, 2013) statistical software.

\subsection{Reliability and Validity of Measures}

The reliability of this study is high because all surveys distributed were exactly the same and can be reused with different sample populations (Walonick, 2012). The surveys included closed-ended questions with dichotomous, multichotomous nominal, or multichotomous ordinal responses. By including responses from all respondents who self-identify as residents of Metro Vancouver, external validity can be increased, and the study results can be generalized to other metropolitan areas with a similar population, such as Toronto. (Walonick, 2012).

\subsection{Inclusion and Exclusion Criteria}

The survey included only responses from participants aged 19 or older who live within Metro Vancouver as defined previously and respond to the survey within a time frame. The survey was administered in January 2015, and responses submitted from January to February 2015 were included in the data analysis.

\subsection{Ethical Considerations}

Since the survey is a human-based study, a cover letter explaining the purpose of the survey and consent was requested prior to the respondent doing the questionnaire. The participant was informed as to who is conducting the research, why and how the information would be used and how the respondent could withdraw from participating at any point of the survey (Ethics Resource Center, 2014). The questionnaire was written in a way to avoid ethical issues and was submitted to course instructors, Helen Heacock and Bobby Sidhu, for ethics approval.

\section{STATISTICAL ANALYSIS}

\subsection{Types of Data}

Nominal, ordinal, and numeric data was gathered from this survey. The nominal and ordinal data collected was either dichotomous or multichotomous. The data that was gathered was described in terms of percentages, proportions, ratios, or rates (Jacobsen, 2012). Questions 1 to 4 of the survey were demographic questions used to assess the age, gender, level of education, and place of residence of the participants. This data was organized into pie charts to visualize the demographic of the sample population. Questions 5 to 10 were knowledge-based questions meant to assess the respondent's knowledge of WTE facilities. These answers were scored to obtain numeric data and analyzed using a t-test or ANOVA to determine if differences existed between the respondent's knowledge of WTE facilities and particular demographics. Questions 11 to 14 pertain to the respondent's opinion of waste management facilities, which were analyzed using the chi square tests. An association between the knowledge of WTE facilities and particular opinions participants may have of them were also assessed.

\subsection{Inferential Statistics and Programs Used}

Questions 5 to 10 were used to assess the respondent's knowledge of WTE facilities and a score was assigned to each question. Since all the survey questions yielded nominal or ordinal data, questions 5 to 10 had a score assigned to each question to get numeric data for analysis (Heacock, personal communication, November 14 2014). For every correct answer, the respondent received one point, to a maximum of five points. A t-test or ANOVA was used to determine whether particular demographics, such as age, have an effect on 
the respondent's knowledge to WTE facilities.

Chi square tests were used to analyze the data collected from questions 11 to 14 . Chi square tests are used with nominal or ordinal data found in survey research and compares a dependent variable with an independent variable (Dawson \& Trapp, 2004).

\section{RESULTS}

Table 1. Age distribution of survey respondents

\begin{tabular}{|l|c|c|c|}
\hline & $\mathbf{N}$ & $\mathbf{\%}$ & Mean Score \\
\hline $19-29$ & 74 & $67 \%$ & 3.6 \\
\hline $30-39$ & 29 & $26 \%$ & 3.4 \\
\hline $40-49$ & 3 & $3 \%$ & 4.7 \\
\hline $50+$ & 5 & $4 \%$ & 3.8 \\
\hline
\end{tabular}

Table 3. Summary of levels of education of survey respondents

\begin{tabular}{|l|c|c|c|}
\hline & N & \% & $\begin{array}{c}\text { Mean } \\
\text { Score }\end{array}$ \\
\hline Less than high school & 0 & $0 \%$ & 0 \\
\hline High school graduate & 8 & $7 \%$ & 3.4 \\
\hline $\begin{array}{l}\text { Three years or less of post- } \\
\text { secondary education } \\
\text { (includes Certificates and } \\
\text { Diplomas) }\end{array}$ & 34 & $31 \%$ & 3.6 \\
\hline $\begin{array}{l}\text { Completion of Bachelor's } \\
\text { degree or higher }\end{array}$ & 69 & $62 \%$ & 3.6 \\
\hline
\end{tabular}

Microsoft Excel was used to organize the survey data and to create any necessary charts and tables (Micosoft, 2014a). NCSS 9 was used to analyze and run statistical tests on the collected data (Hintz, 2013). Microsoft Word was used to organize the final results and to prepare a report of the findings (Microsoft, 2014).

Table 2. Gender distribution of survey respondents

\begin{tabular}{|l|c|c|c|}
\hline & $\mathbf{N}$ & $\mathbf{\%}$ & Mean Score \\
\hline Female & 49 & $44 \%$ & 3.7 \\
\hline Male & 59 & $53 \%$ & 3.6 \\
\hline N/A & 3 & $3 \%$ & 3.7 \\
\hline
\end{tabular}

Table 4. Distribution of places of residences of survey respondents

\begin{tabular}{|l|c|c|c|}
\hline & N & \% & $\begin{array}{c}\text { Mean } \\
\text { Score }\end{array}$ \\
\hline $\begin{array}{l}\text { Vancouver/North } \\
\text { Vancouver }\end{array}$ & 61 & $55 \%$ & 3.5 \\
\hline Burnaby/Coquitlam & 22 & $20 \%$ & 3.6 \\
\hline $\begin{array}{l}\text { New Westminister/Port } \\
\text { Coquitlam/Port } \\
\text { Moody/Surrey }\end{array}$ & 14 & $12 \%$ & 4.1 \\
\hline Richmond/Delta/Langley & 12 & $11 \%$ & 3.9 \\
\hline Other & 2 & $2 \%$ & 4.5 \\
\hline
\end{tabular}

Table 5. Knowledge Scores

\begin{tabular}{|l|c|c|}
\hline & $\mathbf{N}$ & $\mathbf{\%}$ \\
\hline 0 out of 5 & 1 & $1 \%$ \\
\hline 1 out 5 & 3 & $3 \%$ \\
\hline 2 out f 5 & 12 & $11 \%$ \\
\hline 3 out of 5 & 31 & $28 \%$ \\
\hline 4 out of 5 & 38 & $34 \%$ \\
\hline 5 out of 5 & 26 & $23 \%$ \\
\hline & Mean Score & 3.6 \\
\hline & Median & 4 \\
\hline
\end{tabular}

Table 6. Summary table of null hypothesis

\begin{tabular}{|l|l|}
\hline Null (Ho) and Alternate (Ha) Hypothesis & Accept or Reject Null Hypothesis (Ho) \\
\hline $\begin{array}{l}\text { Ho: There is no difference between age group } \\
\text { and knowledge score of WTE facilities. }\end{array}$ & $\mathrm{P}=0.31$ \\
\hline
\end{tabular}


Ha: There is a difference between age group and knowledge score of WTE facilities.

Ho: There is no difference between place of residence and knowledge score of WTE facilities.

Ha: There is a difference between place of residence and knowledge score of WTE facilities.

Ho: There is no difference between educational background and knowledge score of WTE facilities.

Ha: There is a difference between age group and knowledge score of WTE facilities.

Ho: There is no association between materials waste facilities, WTE facilities, and landfills in their ranking of desirability for municipal solid waste management.

Ha: There is an association between materials waste facilities, WTE facilities, and landfills in their ranking of desirability for municipal solid waste management.
Fail to reject Ho: There is no statistically significant difference between age group and knowledge score of WTE facilities.

$\mathrm{P}=0.22$

Fail to reject Ho: There is no statistically significant difference between place of residence and knowledge score of WTE facilities.

$\mathrm{P}=0.51$

Fail to reject Ho: There is no statistically significant difference between educational background and knowledge score of WTE facilities.

$\mathrm{P}=0.0$

Reject Ho: The ranking of materials waste facilities, WTE facilities, then landfills in order of the most desirable to least desirable method of municipal waste management is statistically significant and not a random result. Materials recovery facilities are the most desirable, followed by WTE facilities. Landfills are the least desirable method of municipal solid waste management.

Table 7. Summary of responses when asked to rank "materials recovery facilities", "Iandfills", and WTE facilities" from the most desirable way of municipal waste management to the least desirable way in terms of environmental and human health concerns.

\begin{tabular}{|l|l|l|l|}
\hline & Most Desirable & Neutral & Least Desirable \\
\hline Materials recovery facilities & $76.6 \%$ & $20 \%$ & $3.6 \%$ \\
\hline Landfills & $1.8 \%$ & $21 \%$ & $77.5 \%$ \\
\hline WTE facilities & $21.6 \%$ & $59 \%$ & $18.9 \%$ \\
\hline
\end{tabular}

Table 8. Summary of responses when asked "the government should contract waste collection and disposal out to private companies instead of managing it as a municipality"

\begin{tabular}{|l|c|c|}
\hline & $\mathbf{N}$ & $\mathbf{\%}$ \\
\hline Strongly Agree & 8 & $7 \%$ \\
\hline Agree & 10 & $9 \%$ \\
\hline No Opinion & 31 & $28 \%$ \\
\hline Disagree & 42 & $38 \%$ \\
\hline Strongly Disagree & 20 & $18 \%$ \\
\hline
\end{tabular}

Table 9. Summary of responses when asked "whether or not Metro Vancouver should suspend work towards the WTE facility and explore other options of municipal waste management"

\begin{tabular}{|l|c|c|}
\hline & $\mathbf{N}$ & $\mathbf{\%}$ \\
\hline Strongly Agree & 13 & $12 \%$ \\
\hline Agree & 26 & $23 \%$ \\
\hline No Opinion & 26 & $23 \%$ \\
\hline Disagree & 37 & $33 \%$ \\
\hline Strongly Disagree & 9 & $8 \%$ \\
\hline
\end{tabular}




\section{DISCUSSION}

The results demonstrated that respondents with a higher educational background did not have more accurate knowledge of WTE facilities $(p=0.51)$. This result should be recognized by policy makers of Metro Vancouver that most residents of the area do not have great knowledge of the topic, even those who are more academically educated. To ensure that the residents may understand the motives and decisions for building this WTE facility, better educational campaigns should be a part of the strategy.

In terms of other demographic information, there was no difference between a respondent's age or place of residence with respect to the knowledge score of WTE facilities ( $p=0.31$ and 0.22 , respectively). This suggests a lack of awareness of WTE facilities across Metro Vancouver residents, regardless of age or whether the respondent lives closer or further away from the existing facility.

It was found that $77 \%$ of respondents agreed that landfills are the least desirable way of managing municipal waste. The response with regards to landfills found in this survey is in agreement with the regional district-wide survey performed by Abacus Data (Abacus Data, 2014). They reported that $66 \%$ of respondents felt that the use of landfills is one of the worst ways of managing municipal waste. $21 \%$ of respondents reported they believed WTE facilities are the best way of processing municipal waste between the three options given in the survey. As compared to the Abacus Data survey, which reported 32\% of respondents believe WTE facilities are one of the better ways of processing municipal waste, there appears to be an agreement. These results suggest that Metro Vancouver residents agree that the current method of heavy reliance on landfills is not the best method of waste management and alternatives should be explored, such as
WTE facilities and materials recovery facilities.

While there is a large collection of residents in Vancouver who are vocal about their opposition against the construction of another WTE facility, the opinions that the study captured revealed that there are some residents who are neutral towards the technology (59.0\%), and even open to the technology (21.6\%). It was found that 33.0\% of respondents disagree that Metro Vancouver should suspend work towards the WTE facility and explore other options of municipal waste management - meaning they are in favour of continuing development of the new facility. On the other hand, 23.0\% had no opinion, and $23.0 \%$ agree Metro Vancouver should move on from WTE facilities.

Some interesting comments that were made by respondents in the survey include:

The main issue is misinformation and a lack of educating the public. Most people seem to be against waste to energy facilities but aren't actually educated on the subject. Both WTE facilities and landfills should be considered secondary solutions with diverting waste the primary goal.

I absolutely do not support [WTE] facilities. There are so many superior solutions that I find this solution insulting and embarrassing as a citizen of Vancouver. Our politicians really should be smarter than this.

If due diligence is done before committing to a new [WTE] site, there should be little concern from an environmental standpoint. I also am of the opinion that if modern gas 
scrubbing technology is applied and enforced, there is very little risk in the way of airborne pollution. Applying 2015 knowledge and technology seems better than burying waste in the ground like we have [done] for hundreds of years. Waste will be generated, I think we should use technology to try and minimize the amount going to landfills.

We need concrete information about the amount of damage caused by WTE to human health and the environment. It must also be compared to other forms of waste disposal - like landfills. This information is vital to an evidencebased decision for Metro Vancouver.

It is noted that among the commenters, some are extremely against WTE facilities, regardless of any preventative measures that may help mitigate undesirable consequences. However, there are also those who believe that if adequate scientific research supported the building of such a facility, there is trust in the government that this technology will integrate well with the current methods of waste management found in Metro Vancouver.

\section{LIMITATIONS}

The main limitation of this study was the sample size. Only 111 respondents were reached, and the survey was only open for responses for approximately two weeks due to the researcher's time constraints. Therefore, the results were extrapolated from a very small sample size. Since budget was a restraint in this regard, there was no time nor money to do in-person surveys to capture a more comprehensive make-up of respondents. Furthermore, the survey was distributed via social media. Thus, this may have captured a younger population (aged 20's to middle age) who frequent such platforms, and may not be as representative of Metro Vancouver.

In analyses with small sample sizes, there may be alpha and beta errors in the results analysis. Since no reported p values fall between the ranges that would warrant the consideration of an error, alpha and beta errors were not considered.

The short knowledge portion of the survey, consisting of only five questions, is also a limiting factor. Since the researcher was attempting to capture both the respondent's knowledge and opinion of WTE facilities, the survey was limited in the amount of the questions that could be dedicated to each section. Ensuring that the survey was not too lengthy and cumbersome for the respondent was also one of the factors considered by the researcher.

As with public opinion surveys in general, there is always a struggle with capturing respondents who are neutral about the issue, and those who feel strongly about the issue. The majority of the respondents felt strongly about the topic of WTE facility-use in Metro Vancouver, and therefore responded to the survey. Evidence of this was seen in the comments section of the survey, where a respondent commented that the use of WTE facilities as a "solution [is] insulting and embarrassing as a citizen of Vancouver". Another commented "research from around the world has demonstrated conclusively that modern WTE facilities pose no risk to human health", exhibiting the opinions of a WTE facility advocate.

\section{RECOMMENDATIONS}

Metro Vancouver should consider providing more educational campaigns on WTE facilities to ensure its residents can make an informed decision on whether the use of this technology is beneficial for the community. As shown previously, 59.0\% of 
the survey respondents felt neutral towards WTE facilities, meaning that there is a lack of understanding to even formulate a true opinion. Rather than limiting its educational campaign to a website that is only read when someone searches on the internet about the topic, a proactive approach can be taken. Bus shelter advertisements and informational brochures can be used to raise awareness on the issues of processing municipal solid waste and the use of incineration technology.

Furthermore, Metro Vancouver should consider expanding research regarding municipal waste management methods beyond landfilling and incineration. They may consider researching into materials recovery facilities, since many of the residents seem to be in favour of such alternatives. The extensive reliance in landfills as seen in Metro Vancouver is becoming a pressing problem. Educational campaigns to encourage recycling and composting will also be an overall desirable solution for the issues of how municipal waste should be disposed. Creative solutions such as banning plastic bags, water bottles, and encouraging compost bin use can be employed in conjunction with a landfill alternative to aid Metro Vancouver's goal in becoming the Greenest City by 2020.

The fact that many residents of Metro Vancouver are unsure about the use of WTE facilities may be able to influence policy. As part of the action plan for Metro Vancouver's goal to become the Greenest City in the world by 2020, incineration is described as a prominent component of the plan (Metro Vancouver, 2010). As this plan was written in 2010, the findings of this survey may indicate that the action plan needs refining in some areas. Landfilling and incineration was an area of focus in the original plans. However, it may be necessary for the plans to place more emphasis on recycling and composting to obtain buy-in from the residents of Metro Vancouver. The plan could focus on expanding the Green Bin and Blue Bin Program, as well as divert more funding into existing recycling incentive programs.

\subsection{Future Research Suggestions}

To further expand on the findings of this research, a larger demographic of Metro Vancouver residents should be surveyed to ensure the sample population is reflective of the actual population. With respect to WTE facilities, another survey can be performed to determine what type of WTE facility Metro Vancouver residents would prefer - they may view mass-burn incineration as a bigger source of pollutants than other methods, such as pyrolysis.

A research study on the feasibility of materials recovery facilities in Metro Vancouver can also be conducted. Research on whether there is a large support for this type of facility in Metro Vancouver, and whether or not EHOs believe it is a feasible municipal waste disposal alternative may be a point of interest.

Another future study could investigate the Metro Vancouver ban on disposing organics into the garbage that was recently implemented in 2015, and how this ban has influenced the Green Bin Program. The study can also compare whether the size of the waste that is destined for the landfills has been reduced since the implementation of the Green Bin Program, using existing data.

\section{CONCLUSIONS}

The results indicated a limited knowledge of WTE facilities with the general public. The findings of this public opinion poll indicated that WTE facilities are not well understood in the community, as insufficient knowledge is provided to the public to formulate a consensus on supporting or opposing the use of WTE facilities. As the Environmental Health Officer (EHO) takes a bigger role in healthy built communities in 
British Columbia health authorities, they may act as an educator in regards to WTE facilities and the outcomes from different ways of handling municipal solid waste. Furthermore, they may be part of a consulting team regarding where such a facility may be sited to reduce any negative outdoor air quality issues in the community. Conducting a public opinion survey is an important step for the government as it helps policy-makers determine where funding should be allotted to keep their objectives in line with that of the residents. Furthermore, asking for the public's opinion will encourage them to think about the issue and acknowledge that their opinion is indeed valued by policy makers, thus reducing the outrage they may have if they were not consulted for their opinion.

\section{ACKNOWLEDGEMENTS}

The author would like to thank the BCIT Environmental Health Program faculty and class for all of their encouragement and support throughout the course of this research project. A special thanks to Helen Heacock for providing ongoing support, advice, and guidance for completing this research paper. Finally, a special thanks to Alan Leung for editing this research paper.

\section{COMPETING INTEREST}

The authors declare that they have no competing interest.

\section{REFERENCES}

Abacus Data. (2014 Jun 20). Survey Results. Retrieved from http://nextuse.ca/wpcontent/uploads/2014/09/Waste_Man agement_Survey_Results.pdf

\footnotetext{
Allan, C. (2013 Apr 18). Waste-to-Energy Facility Environmental Monitoring and Reporting, 2012 Update. Retrieved from http://www.metrovancouver.org/serv
}

ices/solidwaste/planning/Recover/W TE/Correspondence/ReportWTEEnv ironmentMonitoringandReporting20 12updatebyChrisAllanforZero WasteCommittee.pdf

Bridges, O., Bridges, J. W., \& Potter, J. F. (2000). A generic comparison of the airborne risks to human health from landfill and incinerator disposal of municipal solid waste. Environmentalist, 20(4), 325334.

Bula, F. (2014 September 16). Survey Calls Metro Vancouver's Waste Incinerator Plan into Question. The Globe and Mail. Retrieved from http://www.theglobeandmail.com/ne ws/british-columbia/survey-callsmetro-vancouvers-waste-incineratorplan-into-question/article20635854/

CEWEP: Confederation of European Wasteto-Energy Plants. (2012). Map of European Waste-to-Energy Plants in 2012. Data \& Info. Retrieved from http://www.cewep.eu/

City of Vancouver. (2015). What Goes in the Recycling Bin. City of Vancouver. Retrieved from http://vancouver.ca/home-propertydevelopment/what-goes-inrecycling-bins.aspx

Constantineau, B. (2014 January 2). Fraser Valley District Considers Legal Action Over Burnaby Incinerator Emissions. The Vancouver Sun. Retrieved from http://www.vancouversun.com/Frase $\mathrm{r}+$ Valley+district+considers+legal $+\mathrm{a}$ ction+over+Burnaby+incinerator+e missions/9344342/story.html 
Covanta. (2015). Energy-from-Waste Facility. Retrieved from http://www.covanta.com/facilities/fa cility-by-location/burnaby.aspx

Dawson, B., \& Trapp, R.G. (2004). Basic and Clinical Biostatistics, $4^{\text {th }}$ edition, McGraw Hill Companies

Department for Environment Food \& Rural Affairs (DEFRA). (2013 Feb). Incineration of Municipal Solid Waste. Retrieved from http://www.gov.uk/

Emery, C. (1994, January). Public Opinion Polling in Canada. Parliament of Canada. Retrieved from http://www.parl.gc.ca/Content/LOP/r esearchpublications/bp371-e.htm\#A. Direct Effects(txt)

Enerkem. (2010). Enerkem Alberta Biofuels. Facilities. Retrieved from http://www.enerkem.com/

Environmental Management Act: Waste Discharge Regulation, B.C. Reg. 320/2004

Ethics Resource Center. (2014). Survey Research: A Summary of Best Practices. Retrieved from http://www.ethics.org/resource/surve y-research-summary-best-practices

Facebook. (2015). Retrieved from facebook.com

Google Docs. (2015). Retrieved from docs.google.com

Health Canada. (2005 Sept). Dioxins and Furans. It's Your Health. Retrieved from http://www.hc-sc.gc.ca/hlvs/iyh-vsv/environ/dioxin-eng.php
Hintz, J. (2013). NCSS 9. NCSS, LLC. Kaysville, Utah USA. www.ncss.com

Jacobsen, K.H. (2012). Introduction to Health Research Methods: A Practical Guide, Jones and Bartlett Learning

Juniper Consultancy Services Ltd. (n.d.). Pyrolysis and Gasification Factsheet. Retrieved from http://www.biomassinnovation.ca/pd f/factsheet_Juniper_Pyrolysis\&Gasif ication.pdf

Metro Vancouver. (2010). Integrated Solid Waste and Resource Management. Retrieved from http://www.metrovancouver.org/abo ut/publications/Publications/ISWRM P.pdf

Metro Vancouver. (2014a). About Us. Retrieved from http://www.metrovnacouver.org/

Metro Vancouver. (2014b). New Waste to Energy. Retrieved from http://www.metrovancouver.org/wte/

Microsoft Corporation. (2014a). Microsoft Excel 2014.

Microsoft Corporation. (2014b). Microsoft Word 2014.

Ministry of Envrionment. (2011 September). Combustion of Municipal Solid Waste. Fact Sheet Air Emissions. Retrieved from http://www2.gov.bc.ca/gov/Downloa dAsset?assetId=4810904D8BB7480 EAB84A5D683F1EC26 
Multi Material BC. (2015). What Happens to my Recycling? Program Overview. Retrieved from http://recyclinginbc.ca/

National Zero Waste Council. (2014). Zero Waste. Retrieved from http://www.nzwc.ca/Pages/default.as $\mathrm{px}$

Petts, J. (1991 July 15). Incineration Risk Perceptions and Public Concern: Experience in the U.K. Improving Risk Communication. Waste Management \& Research, 10, 169182.

Simon, J. \& Ivaylo Hlebarov. (n.d.). Turn the EU Away from More Incineration. Waste and Climate Change. Retrieved from www.noburn.org/

StatPac. (2014). Survey Sample Methods. Retrieved from https://www.statpac.com/surveys/sa mpling.htm

Stengler, E. (2015 January 8). A Europe without Landfills and Russian Gas. Retrieved from http://www.volund.dk/News/2015/01
/12/A_Europe_without_landfills?lan guage $=$ en\&ec as=97B048F5B9FD4C29B9FE1D00 624ED06C

Stop the Incinerator. (2014). Overview. Retrieved from http://www.stoptheincinerator.com

Travis, D. (2014 August 28). Why a Rush to Incinerate Garbage May Burn Metro Vancouver. The Huffington Post. Retrieved from http://www.huffingtonpost.ca/dermo dtravis/metro- vancouver-garbageincinerator_b_3830917.html

United States Environmental Protection Agency. (2014 April 14). Wastes Non-Hazardous Waste - Municipal Solid Waste. Retrieved from http://www.epa.gov/

Walonick, D. (2012). Steps in Designing a Survey. Retrieved from https://www.statpac.com/surveydesign-guidelines.

World Health Organization. (2014 June). Dioxins and their Effects on Human Health. Retrieved from http://www.who.int/mediacentre/fact sheets/fs225/en/ 